Laise, L.D. y Manzo-Ugas, G. Las desviaciones del sistema económico constitucional y el ocaso económico venezolano. Derecho y Ciencias Sociales. Mayo -Octubre 2021. № 25 .Pgs 123-151. ISSN 1852-2971. Instituto de Cultura Jurídica y Maestría en Sociología Jurídica. Facultad de Ciencias Jurídicas y Sociales. Universidad Nacional de La Plata. Argentina.

\title{
Las desviaciones del sistema económico constitucional y el ocaso económico venezolano
}

The Deviations of the Economic Constitutional System and the Twilight of the Venezuelan Economy

Luciano D. Laise y Gustavo Manzo-Ugas`•

\section{Resumen}

La Constitución de la República Bolivariana de Venezuela (1999) sentó las bases del modelo económico que ha de imperar en ese país. Una de las notas más encomiables de tal modelo es que propone una conciliación entre lo colectivo y lo individual, para así poner a la persona en el centro del desarrollo socioeconómico. De esta manera, se reconoce el principio general de libertad en materia económica y, a la vez, se instituyen los pisos mínimos para las designaciones de aquellas autoridades que conducen uno de los segmentos más significativos de la política económica de un Estado: el Banco Central. Sin embargo, tales libertades económicas se han ido restringiendo tan intensamente que se ha llegado al punto que el gobierno nacional es quien determina los precios, junto con la estructura de costos y ganancias de todas las empresas, ya sean estas pertenecientes al sector público o al sector privado. Además, la Asamblea Nacional ha sido apartada en el proceso de designación del Presidente y miembros del Directorio del Banco Central. En este trabajo defenderemos la tesis de que el debilitamiento de la independencia del Banco Central de Venezuela ha derivado en un progresivo debilitamiento de las instituciones constitucionales de corte económico, lo cual se ha agravado en virtud de la escasa transparencia en la gestión y rendición de cuentas de la autoridad monetaria venezolana.

Palabras clave: constitucionalismo abusivo; política económica; derecho constitucional económico.

\begin{abstract}
:
The Constitution of the Bolivarian Republique of Venezuela (1999) has settled the grounds of a specific economic model. One of the most relevant features of that model is that it aims at harmonizing the collective with the individual to put persons at the core of socio-
\end{abstract}

\footnotetext{
- Doctor en Derecho (U. Austral, Argentina). Abogado (Universidad de Buenos Aires). Investigador de planta del Consejo Nacional de Investigaciones Científicas y Técnicas (CONICET), lugar de trabajo: Departamento de Ciencias Sociales, Jurídicas y Económicas, Universidad Nacional de Chilecito, 9 de Julio N. ${ }^{\circ}$ 22, Chilecito, Argentina. ORCID N $\mathrm{N}^{\circ}$. https://orcid.org/0000-0003-4249-5948. E-Mail: lucianolaise@conicet.gov.ar

- Doctor en Derecho (Universidad Central de Venezuela). Abogado (Universidad de Carabobo). Profesor de Teoría Política Constitucional. Facultad de Estudios Jurídicos y Políticos, Universidad Metropolitana, Distribuidor Universidad Autopista Petare-Guarenas, Urbanización Terrazas del Ávila, Caracas, Venezuela. ORCID N : https://orcid.org/0000-0001-8553-501X E-mail: gmanzo@unimet.edu.ve
}

Recibido:30/7/2020 Publicable con correcciones 27/8/2021

https://doi.org/10.24215/18522971e095 
Laise, L.D. y Manzo-Ugas, G. Las desviaciones del sistema económico constitucional y el ocaso económico venezolano. Derecho y Ciencias Sociales. Mayo -Octubre 2021. № 25 .Pgs 123-151. ISSN 1852-2971. Instituto de Cultura Jurídica y Maestría en Sociología Jurídica. Facultad de Ciencias Jurídicas y Sociales. Universidad Nacional de La Plata. Argentina.

economic development. Thus, the Venezuelan constitution recognizes a general principle of liberty. At the same time, it institutes the minimal requirements for the appointment of a public office that drives a significant part of the political economy: the Central Bank. Nevertheless, the national government had limited those liberties and became the one who determines prices and the structure of costs/profits of all enterprises, whether public or private. In this article, we hold the following claim: since the National Assembly takes no intervention at the appointments of the President or Directors of the Central Bank, that had deeply undermined constitutional institutions of economic nature. The opacity and lack of accountability of the Venezuelan monetary office have diluted the constitution's economic features.

Keywords: abusive constitutionalism; political economy; economic constitutional law. 
Laise, L.D. y Manzo-Ugas, G. Las desviaciones del sistema económico constitucional y el ocaso económico venezolano. Derecho y Ciencias Sociales. Mayo -Octubre 2021. № 25 .Pgs 123-151. ISSN 1852-2971. Instituto de Cultura Jurídica y Maestría en Sociología Jurídica. Facultad de Ciencias Jurídicas y Sociales. Universidad Nacional de La Plata. Argentina.

\section{Las desviaciones del sistema económico constitucional y el ocaso económico venezolano*}

Luciano D. Laise y Gustavo Manzo-Ugas

\section{Introducción: de la opacidad en la información económica oficial al deterioro de la república venezolana}

El objeto de esta investigación tiene como punto de partida el hecho de que se han conculcado los postulados económicos constitucionales de la república venezolana. En efecto, resulta de público conocimiento que la actual economía venezolana exhibe notables indicadores de un proceso de empobrecimiento que la coloca en términos de un auténtico desastre humanitario. Con todo, lo llamativo es que se advierte tal fenómeno sin que Venezuela haya sufrido calamidades extraordinarias o devastadoras como un desastre natural de grandes proporciones. Tampoco tuvo lugar ningún enfrentamiento armado de suma magnitud en las últimas décadas.

No obstante, el hecho notorio acerca de la gravedad del problema económico venezolano no implica que se pueda especificar rigurosamente su extensión ${ }^{1}$. De hecho, la precisión de tal panorama económico se enfrenta con una primera dificultad: la opacidad oficial en lo que respecta a cifras e información pública elemente que permita evaluar con rigor y exactitud la gravedad de la crisis económica de la República Bolivariana de Venezuela. Ahora bien, esta opacidad se habría atenuado ya que recientemente se han vuelto a publicar estadísticas oficiales $^{2}$. Sin embargo, hay una gran distancia entre la necesidad de cifras en economía púbicas y lo que sucede en la realidad. En efecto, el directorio del Fondo Monetario Internacional (FMI) ha planteado que "Venezuela no ha implementado las medidas correctivas ni ha suministrado información sobre una serie de datos adicionales requeridos" (FMI, 2018). Lo dicho llega a tal punto que el propio FMI ha emitido "una declaración de censura en contra de Venezuela por no haber implementado las medidas correctivas ni haber cumplido con su obligación en virtud del Artículo VIII, Sección 5"

Este trabajo se inserta en el proyecto "Naturaleza, límites y desafíos del activismo judicial: reflexiones a partir de la jurisprudencia de la Corte Suprema de Justicia de la Nación" (Código DCT2022), financiado por la Facultad de Derecho de la Universidad de Buenos Aires. El orden de los autores resulta estrictamente alfabético.

1 Para uno de los trabajos más recientes que aportan datos empíricos para dimensionar la crisis socioeconómica venezolana, ver Torrealba Méndez (2019).

${ }^{2}$ Igualmente se recomienda la lectura de Vargas et. Al. (2019). 
Laise, L.D. y Manzo-Ugas, G. Las desviaciones del sistema económico constitucional y el ocaso económico venezolano. Derecho y Ciencias Sociales. Mayo -Octubre 2021. № 25 .Pgs 123-151. ISSN 1852-2971. Instituto de Cultura Jurídica y Maestría en Sociología Jurídica. Facultad de Ciencias Jurídicas y Sociales. Universidad Nacional de La Plata. Argentina.

(FMI, 2018). Con otras palabras, la referida nación sudamericana es renuente a brindar datos precisos sobre el estado real de su economía.

Así, las pocas fuentes de información estadística fiable provienen de reportes e indicadores que, por lo general, elaboran instituciones privadas y ONG's que se ubican dentro de Venezuela. Con todo, es cierto que luego cambió la postura del gobierno nacional y desde entonces el Banco Central de Venezuela publica informes estadísticos, pero de manera ostensible se presentan discrepancias que podrán observarse con el desarrollo de este trabajo ${ }^{3}$. En cualquier caso, más allá de la política de información de datos, se encuentran disponibles algunos estudios empíricos que permiten apreciar la relevancia del problema bajo investigación. Además, resulta de público conocimiento que el problema económico en Venezuela ha generado un proceso migratorio que se manifiesta en las propias fronteras de ese país, lo cual llega a amenazar a la estabilidad misma de la región. Dicho de otra manera, la crisis económica venezolana se convierte en un factor que desestabiliza a la región en su conjunto.

Lo mencionado anteriormente se revela paradigmáticamente en el hecho de que grupos muy desamparados son los que están migrando hacia los países limítrofes. Aún más, después de Siria, la República Bolivariana de Venezuela es el país con más desplazados en el mundo (Loey, 2020). De hecho, a principios de 2018 la situación era preocupante, ya que entre los grupos más vulnerables de desplazados se encontraban mujeres, niños, y adolescentes. La situación de los desplazados resulta tan grave y es tan desesperante que el $90 \%$ de las familias sufren la carencia de alimentos o están en riesgo de sufrirla (Loey, 2020).

Ahora bien, uno de los rostros más trágicos del éxodo venezolano es que el $19 \%$ de las personas recurren al trabajo infantil, la explotación sexual, la prostitución y la mendicidad para acceder a alimentos y recursos mínimos para sobrevivir. El acceso al servicio de la salud también es altamente deficiente, ya que el $80 \%$ de los migrantes no tiene acceso a servicios de salud o medicinas. La nutrición de niños, adolescentes y madres es muy precaria. Menos del 3\% de los menores de 6 meses reciben lactancia materna exclusiva y tan solo el $7 \%$ de los niños menores de 2 años reciben alimentación suplementaria (Rugholm, 2018).

Situados en este contexto se puede apreciar que nos encontramos frente a un proceso o crisis económica en la República Bolivariana de Venezuela que en este trabajo se ha

\footnotetext{
${ }^{3}$ Sobre este punto, véase: Ramsbotton (2019).
} 
Laise, L.D. y Manzo-Ugas, G. Las desviaciones del sistema económico constitucional y el ocaso económico venezolano. Derecho y Ciencias Sociales. Mayo -Octubre 2021. № 25 .Pgs 123-151. ISSN 1852-2971. Instituto de Cultura Jurídica y Maestría en Sociología Jurídica. Facultad de Ciencias Jurídicas y Sociales. Universidad Nacional de La Plata. Argentina.

analizado desde el prisma del debilitamiento de los postulados económicos recogidos en el texto constitucional venezolano. Sin embargo, tal proceso tiene la particularidad de que se han ido desmontando múltiples estructuras económicas que, a su vez, han sido reemplazados por nuevos postulados y premisas oficiales. Lo último fue posibilitado a través de una imposición de una verdad oficial, un concepto económico oficial y unas instituciones oficiales. Esto no solo ha implicado la construcción de un relato económico sin fundamento en información confiable, sino también un deterioro sobre la dimensión republicana del estado venezolano.

De esta manera, la tesis que se defenderá en esta investigación es que la crisis de los postulados constitucionales de corte económico se ha reforzado por medio de un debilitamiento de las condiciones de posibilidad del conocimiento mismo de la realidad económica, en nuestro caso-. Porque, en efecto, desde 2015 que el Estado venezolano se abstiene de publicar estadísticas oficiales de naturaleza económica que se condigan adecuadamente con la realidad material (Asamblea Nacional de la República Bolivariana de Venezuela, 2017). Aún más, la crisis económica tiene un correlato de naturaleza informativa que refleja la injerencia creciente del Poder Ejecutivo Nacional sobre las libertades económicas fundamentales y sobre el control político de la economía del país, lo cual ha llegado al extremo de desplazar al parlamento venezolano de esa función de control que caracteriza al poder legislativo en las democracias constitucionales (Aguilar Blancas, 2017; Aragón Reyes, 1986).

La estructura argumentativa para sostener la antedicha tesis será la siguiente: i) se reconstruirán los postulados económicos que se asumen en el derecho constitucional venezolano. Luego, ii) se contrastarán las prácticas y políticas económicas con las aspiraciones constitucionales de naturaleza económica que contiene la Constitución de la República Bolivariana de Venezuela. iii) Posteriormente se evaluarán de manera crítica las implicancias de intentar concretar a las aspiraciones económicas contenidas en la constitución sin la posibilidad de un control parlamento y ciudadano eficaz. Por último, iv) se concluirá con un apartado en que se recapitularán los principales resultados que arrojará esta investigación. 
Laise, L.D. y Manzo-Ugas, G. Las desviaciones del sistema económico constitucional y el ocaso económico venezolano. Derecho y Ciencias Sociales. Mayo -Octubre 2021. № 25 .Pgs 123-151. ISSN 1852-2971. Instituto de Cultura Jurídica y Maestría en Sociología Jurídica. Facultad de Ciencias Jurídicas y Sociales. Universidad Nacional de La Plata. Argentina.

\section{Los postulados económicos de la constitución venezolana: la prioridad de la persona humana como armonización entre lo colectivo y lo individual}

La crisis económica que atraviesa la República Bolivariana de Venezuela ha sido ocasionada por el desmontaje de elementos, características y leyes fundamentales de la economía que han sido plasmados en el texto constitucional venezolano. La explicación de tal fenómeno responde a que estamos frente a un aspecto típico del totalitarismo, porque en tales regímenes se desmonta a la economía y el pacto social que le da sustento institucional - la Constitución-. Esto llega a tal punto en el caso venezolano que el régimen pretende controlar lo político, lo social, lo jurídico y todas las áreas del quehacer humano (Brum, 2011). Por consiguiente, nos encontramos frente a un régimen totalitarista que subsume el individuo a la colectividad y esta, a su vez, se impone por sobre toda persona humana (Arendt, 1958).

Así se puede advertir que, en aquellas sociedades dirigidas por un régimen absolutista o totalitarista, se identifican patrones económicos sociales y jurídicos colmados de la voluntad de poder de una persona o grupo al mando. Tal régimen suele imponer fórmulas económicas, sociales y jurídicas que materializan a esa voluntad totalitaria. Precisamente este es el caso venezolano, en el que el texto constitucional plasma un modelo socioeconómico, pero las prácticas infraconstitucionales orientadas a concretar tales disposiciones constitucionales terminan imponiendo un modelo sustancialmente distinto. Porque, en efecto, la constitución que formalmente adoptó Venezuela no abraza un modelo económico propiamente colectivista, como veremos más adelante.

Ahora bien, la Asamblea Nacional electa en 2015 fue una de las pocas instituciones que funcionó como un cierto contrapeso en el proceso político que atravesó Venezuela en los últimos años ${ }^{4}$. Esta ha sostenido que, para el mes de junio de 2020, la inflación acumulada en términos interanuales se ubicó en el 3.524\% (Infobae, 2020); esto es, se trata del caso de hiperinflación más grave del mundo en la hora presente. De hecho, el Fondo Monetario Internacional estima un índice inflacionario significativamente más grave, el cual asciende al $15.000 \%$, muy por encima del segundo puesto - Zimbawe-que llega al 319\% (FMI, 2020). Con otras palabras, en la citada nación sudamericana se advierte un proceso

\footnotetext{
${ }^{4}$ A la fecha en la cual se elabora la versión final de este artículo (23 de agosto de 2021), el signo político que domina la Asamblea Nacional está sometida por el partido oficialista. Las razones para explicar el cambio de tendencia política son diversas y esto llevaría la investigación a un punto lejano de sus objetivos. Sin embargo, es posible afirmar que perversiones legislativas y fenómenos como el constitucionalismo abusivo han contribuido a la inestabilidad que se observa en cambio tan significativos como el mencionado.
} 
Laise, L.D. y Manzo-Ugas, G. Las desviaciones del sistema económico constitucional y el ocaso económico venezolano. Derecho y Ciencias Sociales. Mayo -Octubre 2021. № 25 .Pgs 123-151. ISSN 1852-2971. Instituto de Cultura Jurídica y Maestría en Sociología Jurídica. Facultad de Ciencias Jurídicas y Sociales. Universidad Nacional de La Plata. Argentina.

inflacionario 47 veces más alto, no compara do con una economía medianamente funcional, sino con el segundo peor caso de inflación en todo el mundo.

Situados en este contexto, anteriormente hemos mencionado que el sistema constitucionaleconómico no es colectivista, lo que nos lleva a la siguiente pregunta, ¿entonces qué modelo económico se desprende de la Constitución de la República Bolivariana de Venezuela? Pues, en primer lugar, cabe mencionar a los artículos $2^{\circ}$ y $3^{\circ}$ de la constitución venezolana, los cuales hacen referencia al marco axiológico sobre el cual se desarrollará la República. Esas disposiciones constitucionales recogen valores tales como la igualdad, solidaridad, justicia, paz, responsabilidad social, ética y el pluralismo político. En lo que respecta específicamente al modelo socioeconómico sobre el que se estructura el estado venezolano, se establece el estado social de derecho como eje cardinal de los actos estatales (Constitución de la República Bolivariana de Venezuela, 1999) ${ }^{5}$.

Estos valores, a su vez, inciden en el régimen y en los postulados económicos que están expresamente plasmados en la Constitución de la República Bolivariana de Venezuela (1999). De manera tal que en el artículo 112 se establece que:

"Todas las personas pueden dedicarse libremente a la actividad económica de su preferencia, sin más limitaciones que las previstas en esta Constitución y las que establezcan las leyes, por razones de desarrollo humano, seguridad, sanidad, protección del ambiente u otras de interés social. El Estado promoverá la iniciativa privada, garantizando la creación y justa distribución de la riqueza, así como la producción de bienes y servicios que satisfagan las necesidades de la población, la libertad de trabajo, empresa, comercio, industria, sin perjuicio de su facultad para dictar medidas para planificar, racionalizar y regular la economía e impulsar el desarrollo integral del país”.

El artículo 113 Constitución de la República Bolivariana de Venezuela (1999) dispone la prohibición de monopolios y carteles. Tal disposición, en efecto, califica al abuso en la posición de dominio en el mercado como hechos contrarios a los postulados constitucionales. Luego, la propia constitución establece que la determinación de responsabilidades y sanciones para estas conductas le corresponde al estado. Dicho con otras palabras, el texto constitucional proscribe toda clase de práctica monopólica con el fin de promover la libertad de elección en los intercambios económicos.

\footnotetext{
${ }^{5}$ Cabe aclarar que la Constitución de la República Bolivariana de Venezuela fue aprobada el 15 de diciembre de 1999, pero recién entró en vigencia en el año 2000 (Tinker Salas, 2015).
} 
Laise, L.D. y Manzo-Ugas, G. Las desviaciones del sistema económico constitucional y el ocaso económico venezolano. Derecho y Ciencias Sociales. Mayo -Octubre 2021. № 25 .Pgs 123-151. ISSN 1852-2971. Instituto de Cultura Jurídica y Maestría en Sociología Jurídica. Facultad de Ciencias Jurídicas y Sociales. Universidad Nacional de La Plata. Argentina.

En el artículo 114 de la mencionada constitución se establece como ilícito económico "a la especulación, el acaparamiento, la usura, la cartelización y otros delitos conexos”, los cuales serán penados con severidad de acuerdo con la ley (Constitución de la República Bolivariana de Venezuela, 1999). De esta manera, la propia constitución desincentiva la concentración económica en perjuicio de una libre competencia y, por añadidura, protege a los consumidores frente a prácticas abusivas.

Luego, en el artículo 115 se establece el derecho a la propiedad, la cual es intensamente protegida, aunque bajo cierto paradigma de la llamada 'función social de la propiedad', ya que esta queda sometida a las contribuciones, restricciones y obligaciones que establezca la ley con fines de utilidad pública o de interés general. Con todo, "solo por causa de utilidad pública o interés social, mediante sentencia firme y pago oportuno de justa indemnización, podrá ser declarada la expropiación de cualquier clase de bienes" (Constitución de la República Bolivariana de Venezuela, 1999).

En el artículo 116 se establece la prohibición de confiscaciones de bienes exceptuando los casos permitidos por la constitución — - . e., una condena con sentencia firme- los bienes de personas naturales o jurídicas —nacionales o extranjeras-, responsables de delitos cometidos contra el patrimonio público; los bienes de quienes se hayan enriquecido ilícitamente al amparo del Poder Público; y, por último, los bienes provenientes de las actividades comerciales, financieras o cualesquiera otras vinculadas al tráfico ilícito de sustancias psicotrópicas y estupefacientes (Constitución de la República Bolivariana de Venezuela, 1999).

No obstante, las disposiciones mencionadas han de complementarse con el modelo socioeconómico sobre el que se afinca el estado venezolano: el Estado Social de Derecho, el cual ha sido recogido en el título VI — artículos 299 al 310 - de la Constitución de la República Bolivariana (1999). De esta manera, la institución del Estado Social de Derecho se ha plasmado en formulaciones normativas como el artículo 299, el cual establece que "El Estado, conjuntamente con la iniciativa privada, promoverá el desarrollo armónico de la economía nacional"; el artículo 302 que prescribe que "El Estado promoverá la manufactura nacional de materias primas provenientes de la explotación de los recursos naturales no renovables". O bien el artículo 305 cuando dispone que "El Estado promoverá la agricultura sustentable como base estratégica del desarrollo rural integral".

Asimismo, la actividad recaudatoria del estado venezolano también está impregnada de los valores que se desprenden del llamado 'Estado Social de Derecho'. Es por ello que en el 
Laise, L.D. y Manzo-Ugas, G. Las desviaciones del sistema económico constitucional y el ocaso económico venezolano. Derecho y Ciencias Sociales. Mayo -Octubre 2021. № 25 .Pgs 123-151. ISSN 1852-2971. Instituto de Cultura Jurídica y Maestría en Sociología Jurídica. Facultad de Ciencias Jurídicas y Sociales. Universidad Nacional de La Plata. Argentina.

artículo 316 se ha adoptado un sistema tributario que se basa expresamente en los siguientes principios: "la justa distribución de las cargas públicas según la capacidad económica del contribuyente, el principio de progresividad, la protección de la economía nacional y la elevación del nivel de vida de la población" (Constitución de la República Bolivariana de Venezuela, 1999).

Más adelante, en la propia constitución se hace referencia al sistema monetario nacional, atribuyendo al Banco Central de Venezuela una competencia regulatoria de forma exclusiva. Así el artículo 318, en su segundo párrafo, dispone lo siguiente:

"El Banco Central de Venezuela es persona jurídica de derecho público con autonomía para la formulación y el ejercicio de las políticas de su competencia. El Banco Central de Venezuela ejercerá sus funciones en coordinación con la política económica general, para alcanzar los objetivos superiores del Estado y la Nación”.

Para el adecuado cumplimiento de su objetivo, el Banco Central de Venezuela tendrá entre sus funciones las de formular y ejecutar la política monetaria, participar en el diseño y ejecutar la política cambiaria, regular la moneda, el crédito y las tasas de interés, administrar las reservas internacionales, y todas aquellas que establezca la ley (Constitución de la República Bolivariana de Venezuela 1999)”.

Posteriormente el artículo 319 recoge los principios que han de guiar la acción económica del Banco Central de Venezuela:

"El Banco Central de Venezuela se regirá por el principio de responsabilidad pública, a cuyo efecto rendirá cuenta de las actuaciones, metas y resultados de sus políticas ante la Asamblea Nacional, de acuerdo con la ley. También rendirá informes periódicos sobre el comportamiento de las variables macroeconómicas del país y sobre los demás asuntos que se le soliciten e incluirá los análisis que permitan su evaluación. El incumplimiento sin causa justificada del objetivo y de las metas, dará lugar a la remoción del directorio y a sanciones administrativas, de acuerdo con la ley.

El Banco Central de Venezuela estará sujeto al control posterior de la Contraloría General de la República y a la inspección y vigilancia del organismo público de supervisión bancaria, el cual remitirá a la Asamblea Nacional informes de las inspecciones que realice. El presupuesto de gastos operativos del Banco Central de Venezuela requerirá la discusión y aprobación de la Asamblea Nacional y sus cuentas y balances serán objeto de auditoría externa en los términos que fije la ley" 
Laise, L.D. y Manzo-Ugas, G. Las desviaciones del sistema económico constitucional y el ocaso económico venezolano. Derecho y Ciencias Sociales. Mayo -Octubre 2021. № 25 .Pgs 123-151. ISSN 1852-2971. Instituto de Cultura Jurídica y Maestría en Sociología Jurídica. Facultad de Ciencias Jurídicas y Sociales. Universidad Nacional de La Plata. Argentina.

Finalmente, cabe mencionar al artículo 320, el cual prescribe que "El Estado debe velar por la estabilidad económica, de precios y monetaria para asegurar el bienestar social”. Esta disposición constitucional, en efecto, plasma en la ley fundamental una carta de navegación para la política económica venezolana. Aún más, se instituye que el horizonte de sentido de toda la economía es el bienestar social y, a la vez, que el Estado es el responsable de la concreción de tal programa económico.

\section{El texto constitucional como punto de partida de la política económica del estado venezolano}

\subsection{Tres nociones preliminares para la vinculación entre política económica y} constitucionalismo

La imbricación entre estado y políticas económicas establecida en la Constitución de la República Bolivariana de Venezuela comprende muchos aspectos que superan ampliamente los objetivos de esta investigación, por lo que aquí se resaltarán aquellos que resultan más estrechamente vinculados a la temática central de este trabajo. Así, con el fin de reconstruir el modelo económico que adoptó la constitución venezolana, se abordará la respuesta a tres preguntas fundamentales: i) qué producir; ii) cómo producirlo y iii) a quién distribuirlo (Valeriano García, 2000).

i) La primera pregunta - qué producir - refiere al hecho de que las distintas organizaciones que se erigen dentro de la sociedad se han visto siempre ante el desafío de establecer un método para elegir qué producir. Se trata, en efecto, de escoger que es lo que se ha de producir en un marco de recursos limitados o escasos. Por ejemplo, los faraones egipcios debían elegir entre construir más palacios o edificar más pirámides. Y, más modernamente, debemos escoger si producimos más aeropuertos o mejores caminos terrestres (Valeriano García, 2000).

La respuesta a qué producir incide significativamente en la vida económica de una comunidad política como el estado. Se trata del problema del llamado 'costo de oportunidad'; es decir, al escoger un bien o servicio que será elaborado se está optando por dejar de lado a la producción de otro bien o servicio (Russell, 2018). Sin embargo, en caso de que se trate de un bien que es requerido por los seres humanos persistirá la necesidad de obtenerlo (Valeriano García, 2000). Por ejemplo, la decisión por la cual se escoge renovar el aeropuerto internacional de una ciudad implicará menos recursos para mejorar las rutas 
Laise, L.D. y Manzo-Ugas, G. Las desviaciones del sistema económico constitucional y el ocaso económico venezolano. Derecho y Ciencias Sociales. Mayo -Octubre 2021. № 25 .Pgs 123-151. ISSN 1852-2971. Instituto de Cultura Jurídica y Maestría en Sociología Jurídica. Facultad de Ciencias Jurídicas y Sociales. Universidad Nacional de La Plata. Argentina.

terrestres de estado, pero estas no dejarán de ser necesitadas por el hecho de que se está refaccionando un aeropuerto de importancia estratégica.

(ii) La segunda cuestión radica en determinar cómo se producirán los bienes y servicios. Esto refiere a que hemos de optar entre diversas técnicas de producción. En efecto, un mismo bien o servicio puede elaborarse con técnicas sustancialmente distintas. Por caso, India produce trigo y otros productos agrícolas con técnicas muy intensivas en lo que respecta al uso de mano de obra. En cambio, los Estados Unidos, y algunos países latinoamericanos, cultivan con métodos productivos muy avanzados que optimizan al capital invertido y, a la postre, terminan contratando una cantidad significativamente menor de trabajadores (Valeriano García, 2000). Dicho de otra manera, existen diversos caminos para elaborar un bien y un servicio, cada uno de los cuales implica una distinta combinación de los factores de producción.

iii) Finalmente, resta preguntarse: ¿a quién distribuirlo? La Constitución venezolana ha adoptado un modelo de Estado Social de Derecho, lo que funciona como una fórmula que posibilita conciliar ideas diversas que tienen origen en la política agonal, pero que se concretan a través de la ley fundamental y otras formulaciones normativas infraconstitucionales (Jiménez Ramírez, 2016). Así, en diferentes artículos del texto fundamental, se define al pueblo como el destinatario de la distribución económica. Por ende, el horizonte de sentido de las regulaciones económicas apunta a incrementar el bienestar de la colectividad en su conjunto.

Sin embargo, cabe remarcar que el sistema constitucional venezolano procura armonizar lo social y lo individual; esto es, no se incurre en una consideración puramente colectivista, como tampoco individualista, en tanto y en cuanto se ubica a la persona como destinatario del mundo económico. De esta manera, la primacía del bien común político sobre el individuo no es unilateral; es decir, el individuo es una parte del todo, conserva una parte del dominio de sí, lo cual implica que este no termina disolviéndose enteramente en el torrente colectivo (Hervada, 2011). Dicho de otra forma, la distribución económica no conlleva necesariamente un programa de tipo colectivista, ya que la persona no es reducida a servir como una pieza fungible de la maquinaria social.

Ahora bien, estas distribuciones son efectuadas por el gobierno del Estado mediante diversas clases o grados de intervenciones sobre la economía. Un hipotético grado extremo se presentaría en el caso en que el estado no participase de modo alguno en la producción de bienes y servicios y, por ende, la función productora estaría completamente a cargo de 
Laise, L.D. y Manzo-Ugas, G. Las desviaciones del sistema económico constitucional y el ocaso económico venezolano. Derecho y Ciencias Sociales. Mayo -Octubre 2021. № 25 .Pgs 123-151. ISSN 1852-2971. Instituto de Cultura Jurídica y Maestría en Sociología Jurídica. Facultad de Ciencias Jurídicas y Sociales. Universidad Nacional de La Plata. Argentina.

las empresas privadas. En el extremo opuesto se ubicarían las economías centralmente planificadas, en las cuales todo se produce en virtud de un plan diseñado y llevado adelante por el sector público y, sobre todo, este tendría el control de los medios de producción (Astudillo Moya, 2012).

En síntesis, se advierte que el desarrollo de la economía dentro de un estado, organizado de manera moderna, conlleva una articulación entre estado y políticas económicas que se traduce en un determinado nivel de intervención gubernamental en lo que respecta a la respuesta a tres cuestiones básicas o fundamentales: qué producir, cómo producirlo, y cómo distribuir lo que se produce en un estado. Con todo, esas intervenciones estatales sobre la economía suelen ser llevadas a cabo mediante organismos, agencias o entidades públicas. Sobre este último punto nos explayaremos en el próximo subapartado.

\subsection{La organización administrativa de la intervención estatal sobre la economía venezolana}

La articulación entre gobierno del Estado y economía es una cuestión que admite diversos grados o niveles. De hecho, algunos estados presentan un mayor nivel de intervención sobre la economía y en otros se advierte una menor intensidad. En cualquier caso, lo cierto es que tal intervención se efectúa a través de diferentes órganos o entidades que pertenecen el sector público.

Ahora bien, una parte de la intervención económica del Estado se puede canalizar a través de las decisiones y actuaciones del Ministerio de Economía y Finanzas, el de Planificación, el de Producción o el de Obras Públicas. Tales carteras ministeriales son las que conciben, planifican, disponen, conciben y/o aplican elementos que hacen tanto a la recaudación como a la actividad erogatoria del Estado. De esta manera, el presupuesto, los gastos públicos, los incentivos fiscales, la ampliación o restricción de las libertades económicas en los términos permitidos por la Constitución son algunos de los ámbitos en que tales organismos pueden ejercer sus competencias mediante la regulación del alcance de las libertades que tienen las personas sobre sus bienes económicos. En otras palabras, la política económica que dirige el gobierno del Estado se encauza - principal, pero no únicamente- a través de sus carteras ministeriales. 
Laise, L.D. y Manzo-Ugas, G. Las desviaciones del sistema económico constitucional y el ocaso económico venezolano. Derecho y Ciencias Sociales. Mayo -Octubre 2021. № 25 .Pgs 123-151. ISSN 1852-2971. Instituto de Cultura Jurídica y Maestría en Sociología Jurídica. Facultad de Ciencias Jurídicas y Sociales. Universidad Nacional de La Plata. Argentina.

Pero, además, el poder legislativo lleva a cabo una función de control sobre las competencias que corresponden a la rama ejecutiva ${ }^{6}$. De hecho, también en la inmensa mayoría de los estados — salvo en el caso de Andorra, Mónaco, Ciudad del Vaticano y las Islas Marshall— se advierte la existencia de un Banco Central, el cual goza de cierto nivel de autonomía para fijar determinadas políticas que mantengan la estabilidad monetaria con el fin de impulsar el crecimiento, el empleo, la propiedad privada, la circulación de capitales, el aumento de las riquezas. El punto es que, por lo general, el Banco Central goza de la autonomía suficiente para no verse enteramente subordinado al Poder Ejecutivo o al Poder Legislativo. De esta manera, se pretende que las decisiones económicas - y sus subsiguientes concreciones mediante el ejercicio de la potestad reglamentaria - sean controladas por las dos ramas del poder político.

Situados en este contexto, es posible preguntarse, ¿cuál fue la vinculación administrativa del Banco Central de Venezuela con los poderes políticos - poder ejecutivo y poder legislativo-? ¿Cómo fue que intervino el poder judicial para asegurar la autonomía del Banco Central de la República Bolivariana de Venezuela? Un abordaje a la teoría y práctica macroeconómica venezolana, y su respectivo anclaje con lo dispuesto en la constitución, permitirá comprender la deriva constitucional y el consiguiente ocaso de la economía de la citada nación sudamericana. Sobre estos puntos versará el próximo apartado.

\section{Balance crítico: de la teoría a la práctica macroeconómica en la República Bolivariana de Venezuela}

\subsection{Valoración crítica del Plan Simón Bolívar (2007-2013): el comienzo de la debacle} económica venezolana

La historia reciente de la economía venezolana, y más en específico en el plano infraconstitucional, revela que en el año 2007 tuvo lugar el plan de desarrollo del denominado "Plan Simón Bolívar 2007-2013”, el cual se dirigió explícitamente a construir el socialismo del Siglo XXI (Chávez Frías, 2008). En las páginas que siguen se efectuará

\footnotetext{
${ }^{6}$ Se asume aquí que los órganos de gobierno de una democracia constitucional realizan dos funciones distintas, pero interrelacionadas: i) la función gubernamental, que está a cargo del Poder Ejecutivo y de la mayoría legislativa, la cual consiste en el trazado de la política global y de todo lo necesario para implementarla y ii) la función de control, que está cargo del Poder Judicial y la minoría legislativa, la cual se dirige a limitar el poder en favor de los valores y principios condicionantes de la actividad estatal (Santiago, 1999).

${ }^{7}$ Para un desarrollo jurisprudencial de este punto, véase Tribunal Supremo de Justicia de la República Bolivariana de Venezuela, Sala Constitucional, 2019.
} 
Laise, L.D. y Manzo-Ugas, G. Las desviaciones del sistema económico constitucional y el ocaso económico venezolano. Derecho y Ciencias Sociales. Mayo -Octubre 2021. № 25 .Pgs 123-151. ISSN 1852-2971. Instituto de Cultura Jurídica y Maestría en Sociología Jurídica. Facultad de Ciencias Jurídicas y Sociales. Universidad Nacional de La Plata. Argentina.

una crítica de cuatro de sus postulados fundamentales. Se han escogido esos cuatros postulados porque funcionan como el punto de partida o premisa fundamental a partir de la cual se estructura el modelo socioeconómico que instauró la llamada revolución bolivariana para el presente siglo.

Así, el mencionado plan contiene, entre otras, las siguientes directrices:

1. Nueva Ética Socialista: Propone la refundación de la Nación Venezolana, la cual hunde sus raíces en la fusión de los valores y principios más avanzados de las corrientes humanistas del socialismo y de la herencia histórica del pensamiento de Simón Bolívar (Chávez Frías, 2008).

2. La Suprema Felicidad Social: A partir de la construcción de una estructura social incluyente, un nuevo modelo social, productivo, humanista y endógeno, se persigue que todos vivamos en similares condiciones, rumbo a lo que decía El Libertador: "La Suprema Felicidad Social” (Chávez Frías, 2008).

3. Democracia Protagónica Revolucionaria: Para esta nueva fase de la Revolución Bolivariana se consolidará la organización social, a fin de transformar su debilidad individual en fuerza colectiva, reforzando la independencia, la libertad y el poder originario del individuo (Chávez Frías, 2008).

4. Modelo Productivo Socialista. Con el fin de lograr trabajo con significado, se buscará la eliminación de su división social, de su estructura jerárquica y de la disyuntiva entre la satisfacción de las necesidades humanas y la producción de riqueza subordinada a la reproducción del capital (Chávez Frías, 2008).

Las mencionadas directrices revelan que los postulados de la economía venezolana se estructuran mediante una planificación centralizada por el término de siete años (20072013). Tal decisión posee rasgos y características socialistas-marxistas en lo que respecta a sus presuposiciones teóricas. De hecho, es posible notar una coincidencia entre las directrices y los postulados centrales del materialismo histórico como, por ejemplo, la eliminación de las clases sociales, el traspaso de los medios de producción (tierra, trabajo y capital) a manos del Estado, la eliminación de la propiedad privada, eliminación del mercado libre y el establecimiento de la igualdad absoluta (Bobbio, 2000). Y, además, la planificación centralizada de la economía es una nota saliente de todo modelo socialista que se pone de relieve en los ejemplos de la ex Unión Soviética, los países Europa oriental 
Laise, L.D. y Manzo-Ugas, G. Las desviaciones del sistema económico constitucional y el ocaso económico venezolano. Derecho y Ciencias Sociales. Mayo -Octubre 2021. № 25 .Pgs 123-151. ISSN 1852-2971. Instituto de Cultura Jurídica y Maestría en Sociología Jurídica. Facultad de Ciencias Jurídicas y Sociales. Universidad Nacional de La Plata. Argentina.

bajo la 'cortina de hierro' y, en América Latina, el caso cubano y el experimento nicaragüense (Mejía-Ortega \& Franco-Giraldo, 2007).

Esta raíz de corte marxista en el plan Bolívar se advierte en que la revolución socialista no ha de cooptar simplemente los resortes del poder político, sino que el aparato del que la burguesía se ha servido precisa ser demolido y reemplazado por instituciones enteramente distintas. Porque, en efecto, la ejecución del citado plan económico no implicó tan solo una atención más reposada a una agenda política que atendiera más eficaz y eficientemente a demandas sociales de los sectores tradicionalmente más relegados de la sociedad venezolana. El plan "Simón Bolívar” implicó un rediseño de los pilares económicos fundamentales del Estado que, a la vez, coexiste con hábitos de consumo y un individualismo propios de sociedades capitalistas (Tinker Salas, 2015).

Ahora bien, cabría plantearse si los postulados del denominado plan Simón Bolívar (20072013) resultan adecuados a lo dispuesto por la constitución de la República Bolivariana de Venezuela. El primer postulado de ese plan, en efecto, resulta contrario a la constitución, la cual asegura una prioridad de la protección de la persona humana ${ }^{8}$. Esa primera directriz instituye un modelo de ética socialista en que ya no se procura conciliar lo individual con lo colectivo con el fin de reafirmar la centralidad de la persona humana. La ética socialista, en contraste, propugna una prioridad absoluta de lo colectivo sobre lo individual, al menos hasta el advenimiento de la sociedad propiamente comunista. De esta manera, ya no cabe espacio para concebir a la búsqueda del propio bien como condición básica para el bien común político. La persona queda sometida a funcionar como una pieza del andamiaje colectivo.

En el segundo postulado se resalta la expresión "que todos vivamos en similares condiciones". Esa afirmación, en principio, no resulta necesariamente contraria al modelo de democracia constitucional adoptado en Venezuela, en la medida en que todos los individuos en la sociedad dispongan de condiciones iguales para desarrollar su personalidad sin limitaciones externas. Se podría plantear, en efecto, que tal postulado resulta una suerte de derivación tanto del principio constitucional de igualdad ${ }^{9}$ (Artículo

\footnotetext{
${ }^{8}$ La noción de 'prioridad de la persona' pretende sintetizar que la persona humana tiene una prioridad tanto en un plano cronológico como en lo que respecta a la fundamentación de toda decisión que compromete a los órganos del gobierno; desde la creación de la constitución hasta su aplicación en casos concretos (Finnis, 2013).

${ }^{9}$ De Fazio plantea que el principio de igualdad ante la ley tradicionalmente se ha utilizado para defender normativamente a los derechos individuales. Sin embargo, nada obsta a que también se lo utilice para exigir la operatividad de bienes colectivos como, por ejemplo, el bienestar general de la sociedad (Fazio, 2019).
} 
Laise, L.D. y Manzo-Ugas, G. Las desviaciones del sistema económico constitucional y el ocaso económico venezolano. Derecho y Ciencias Sociales. Mayo -Octubre 2021. № 25 .Pgs 123-151. ISSN 1852-2971. Instituto de Cultura Jurídica y Maestría en Sociología Jurídica. Facultad de Ciencias Jurídicas y Sociales. Universidad Nacional de La Plata. Argentina.

$21^{\circ}$, Constitución de Constitución de la República Bolivariana de Venezuela) como del derecho fundamental al libre desarrollo de la personalidad (Artículo 20º Constitución de Constitución de la República Bolivariana de Venezuela). Más aún, el ordenamiento constitucional venezolano expresamente dispone la indivisibilidad e interdependencia de los derechos humanos (Artículo 19², Constitución de Constitución de la República Bolivariana de Venezuela).

Asimismo, este segundo postulado está intrínsecamente conectado a la operatividad de los derechos sociales. Porque, en efecto, uno de los fundamentos sobre los que reposa la exigibilidad de tales derechos precisamente consiste en avanzar hacia en el remedio de desigualdades profundas en el tejido social (Gargarella, 2011). Esto es algo que se manifiesta paradigmáticamente en países latinoamericanos como Venezuela, en donde el consolidado modelo rentístico se concentraba en actividades económicas extractivas cuyos beneficios se distribuían socialmente, pero sin llegar a remediar sustancialmente la desigualdad socioeconómica (Leon, 2020).

No es que no hubiera avances en los indicadores sociales de ningún tipo, al menos durante el gobierno de Chávez. El punto es que ese modelo rentístico no logró afianzar vínculos sociales que fomentasen emprendimientos que permitieran a las personas dejar atrás a la pobreza (Leon, 2020). Por ejemplo, en 2012 los indicadores socioeconómicos presentaron una mejora en términos de reducción de la desigualdad, ya que el coeficiente Gini en Caracas y en Venezuela disminuyó 0.4. Sin embargo, la inseguridad ciudadana, tanto a nivel urbano como nacional se ubicaba entre las más altas de la región (Zubillaga, 2013). Según el último estudio de la United Nations Office of Drugs and Crime (2019), la situación se agravó a tal punto que en Venezuela se registra 56.8 homicidios cada cien mil habitantes, lo cual implica una de las tasas más altas del mundo para países que no sufren conflictos armados (United Nations Office on Drugs and Crime, 2019). Cabe aclarar que, a nivel mundial, Venezuela solo se ubica por detrás del estado salvadoreño, el cual registra 62.1 homicidios cada cien mil habitantes (United Nations Office on Drugs and Crime, 2019).

Lo dicho anteriormente pretende remarcar la importancia de que ese postulado que aspira a "que todos vivamos en similares condiciones" no refiere únicamente a condiciones socioeconómicas dignas y suficientes para asegurar la vida humana. De lo que se trata es concretar un proceso de inclusión social que incorpore tanto el remedio a la desigualdad como el mantenimiento de adecuados niveles de seguridad ciudadana. De manera tal que 
Laise, L.D. y Manzo-Ugas, G. Las desviaciones del sistema económico constitucional y el ocaso económico venezolano. Derecho y Ciencias Sociales. Mayo -Octubre 2021. № 25 .Pgs 123-151. ISSN 1852-2971. Instituto de Cultura Jurídica y Maestría en Sociología Jurídica. Facultad de Ciencias Jurídicas y Sociales. Universidad Nacional de La Plata. Argentina.

los habitantes de Venezuela puedan desarrollar sus actividades de una manera suficientemente libre y segura, sin sufrir ataques violentos a su integridad física o patrimonial. Con otras palabras, remediar la desigualdad venezolana implica no solo erradicar altos niveles de pobreza, sino también — entre otras cosas - resolver el problema de la inseguridad ciudadana que impide que el país se desarrolle y prospere. Al fin y al cabo, los derechos sociales están intrínsecamente conectados con el resto de los derechos fundamentales, tal como formalmente lo reconoce la propia Constitución de la República Bolivariana de Venezuela (Artículo $1^{\circ}$ ).

Ahora bien, cabría plantearse si el tercer postulado - la "Democracia Protagónica Revolucionaria"- resulta constitucional. La respuesta parecería ser negativa, porque ese postulado se dirige a la modificación de las estructuras sociales y para ello pretende apuntalarse en el poder originario del individuo. Sin embargo, las estructuras de la sociedad venezolana están adecuadamente establecidas en la propia constitución. Tales estructuras tienen como punto de partida a la familia, la cual es la base fundamental de la sociedad y a partir de ella se genera una gran armazón de instituciones que surcan el modelo de desarrollo personal y colectivo de todo el pueblo venezolano ${ }^{10}$ (Artículo $75^{\circ}$ y ss., Constitución de la República Bolivariana de Venezuela).

Con todo, lo más sorprendente de esta llamada "Democracia Protagónica Revolucionaria" es que cuando se hace referencia al poder originario del individuo, en realidad, se advierte que la finalidad subyacente consiste en alterar radicalmente a las estructuras sociales a partir del poder de las mayorías. Estas pueden realmente transformarlo "todo", yendo incluso por encima de lo dispuesto por la constitución. En tal sentido, el citado plan Simón Bolívar recoge expresamente la siguiente definición:

"Dado que la soberanía reside en el pueblo, este puede por sí mismo dirigir el Estado, sin necesidad de delegar su soberanía, tal como en la práctica sucede con la democracia representativa o indirecta, esta dirección del Estado está indisolublemente unida a la búsqueda del bien común, y no como en la democracia representativa en la que, bajo la argucia de la libertad individual, con el camuflaje de la "igualdad de oportunidades" y el acicate de la competitividad, se legitima el interés de grupos minoritarios contrapuestos al interés general de la sociedad"

\footnotetext{
10 Este punto tiene una cierta reminiscencia a la filosofía social de Aristóteles, en tanto que el estagirita afirmaba que una nación es un conjunto de hogares, tierras y propiedades autosuficientes que se dirigen a lograr que sus habitantes puedan llevar adelante una "buena vida" (Aristotle, 2014).
} 
Laise, L.D. y Manzo-Ugas, G. Las desviaciones del sistema económico constitucional y el ocaso económico venezolano. Derecho y Ciencias Sociales. Mayo -Octubre 2021. № 25 .Pgs 123-151. ISSN 1852-2971. Instituto de Cultura Jurídica y Maestría en Sociología Jurídica. Facultad de Ciencias Jurídicas y Sociales. Universidad Nacional de La Plata. Argentina.

Lo dicho anteriormente se lleva a cabo mediante la tipificación penal de conductas que están dirigidas a producir daños al colectivo o a la sociedad amparada en el ordenamiento legal y constitucional. Así, por ejemplo, se sancionaron algunas reformas al Código Penal en el año 2000 y 2005. En tales reformas se han introducido tipos penales que incorporan clausulas generales como, por caso, el Artículo 296a del Código Penal de Venezuela, el cual introdujo el llamado delito de 'terrorismo informativo'; esto es, quien por medio de informaciones falsas difundidas por cualquier medio "causare pánico en la colectividad o la mantenga en zozobra". De esta manera, se ha potenciado la expansión del derecho penal y el sistema jurídico-penal se ha alejado de los postulados centrales del Estado Constitucional de Derecho (Rosales, 2006). Porque se ha intensificado la fuerza del aparato represivo estatal no con el fin último de asegurar una mayor libertad de los ciudadanos, sino con el propósito de disciplinar aquellas conductas que no se corresponden con la voluntad del gobierno de turno.

4.2. Toma I: algunos aspectos problemáticos de la planificación centralizada de la economía de espalda a la constitución: el sistema venezolano de fijación de precios

Se pueden apreciar otros elementos de la práctica económica venezolana que socavan los postulados económicos constitucionales en los años posteriores al 2014. En efecto, a través de una llamada 'Ley Habilitante', publicada en la Gaceta Oficial No. 6.112 extraordinario, de fecha 19/11/2013 — cuya vigencia culminó el día 19 de noviembre de 2014-, el Poder Ejecutivo Nacional fue autorizado a emitir legislación de fondo. De esta manera, la presidencia venezolana dictó cincuenta y seis (56) Decretos-Leyes, en los cuales se inscribe el Plan Simón Bolívar original y sus subsecuentes prórrogas que llevaron consigo diferentes complementos. Eso implicó la progresiva demolición del modelo económico plasmado en la Constitución de la República Bolivariana de Venezuela. En las páginas que siguen se describirán algunos de tales decretos y, además, se los contrastará con los postulados económico-constitucionales que rigen en Venezuela desde el año 1999.

Por medio de tal delegación al Poder Ejecutivo Nacional para legislar en cuestiones de fondo se puso en vigencia la ley del Centro Nacional de Comercio Exterior y de la Corporación Venezolana de Comercio Exterior en la Gaceta Extraordinaria n. ${ }^{\circ}$ 6.116, de fecha 29/11/2013, la ley de Reforma Parcial de la Ley Contra los Ilícitos Cambiarios en la Gaceta Extraordinaria N. ${ }^{\circ}$ 6.117, de fecha 4/12/2013 la reforma parcial de la ley Orgánica de Precios Justos publicada en la Gaceta Ordinaria N. ${ }^{\circ}$ 40.340, de fecha 23/01/2014, Ley 
Laise, L.D. y Manzo-Ugas, G. Las desviaciones del sistema económico constitucional y el ocaso económico venezolano. Derecho y Ciencias Sociales. Mayo -Octubre 2021. № 25 .Pgs 123-151. ISSN 1852-2971. Instituto de Cultura Jurídica y Maestría en Sociología Jurídica. Facultad de Ciencias Jurídicas y Sociales. Universidad Nacional de La Plata. Argentina.

Orgánica que Reserva al Estado las Actividades de Exploración y Explotación de Oro, así como las Conexas y Auxiliares a Éstas, Ley de Reforma Parcial del Decreto con Rango, Valor y Fuerza de Ley de Tasas Portuarias, Ley que Reforma Parcialmente la Ley de Timbres Fiscales, Ley del Régimen Cambiario y sus Ilícitos, Ley del Sistema Nacional Integral Agroalimentario, Ley de Reforma del Decreto con Rango, Valor y Fuerza de Ley de Pesca y Acuicultura. Todas con una incidencia importante en términos de la economía del estado.

Así, por ejemplo, entre las medidas anunciadas por el presidente venezolano, Nicolás Maduro, durante su intervención ante la Asamblea Nacional Constituyente (ANC) el 7/09/2017 cabría mencionar a las siguientes: (i) el establecimiento de precios en cincuenta (50) rubros mediante un nuevo sistema de fijación de precios; (ii) la institución de mecanismos de fiscalización que son ejecutados por los concejos comunales organizados con el fin de vigilar tales precios fijos; (iii) la implementación de un nuevo sistema de pagos para obligaciones internacionales basado en monedas distintas al dólar estadounidense; iv) el establecimiento de casas de cambio; y v) la rebaja de 5\% en el IVA para quienes hagan uso de la tarjeta de débito o pago electrónico, todo con el fin de luchar contra la autoproclamada "guerra económica".

Asimismo, por medio de la Asamblea Nacional Constituyente fue puesta en vigencia la Ley Constitucional de Precios Acordados, publicada en la Gaceta Oficial Extraordinaria N. ${ }^{\circ} 6.342$ de fecha 22 de noviembre de 2017. Esta ley, aun cuando en sus artículos iniciales hace referencia a postulados que eventualmente pueden ser considerados inocuos, en su artículo 9 fija una posición inequívoca en cuanto a las políticas económicas vigentes en Venezuela. En efecto, la antedicha disposición constitucional establece que la intervención del Estado en el proceso productivo industrial y comercial es absoluta, ya que afecta a todos los aspectos de los procesos económicos que mencionamos anteriormente en este mismo trabajo. Por ende, esa ley establece que el gobierno es capaz de intervenir en los tres momentos centrales de la economía; esto es, el gobierno nacional tiene la potestad para determinar: i) qué se produce; ii) cómo producir y iii) a quién distribuir lo que se ha elaborado.

Más en concreto, el Artículo $9^{\circ}$ de la Ley Constitucional de Precios Acordados establece que "Los sectores privado, público, comunal, y de las trabajadoras y trabajadores del área de la producción, distribución y comercialización, presentarán sus estructuras de costos, mediante una notificación formal de costos y precios ante la Vicepresidencia Ejecutiva de 
Laise, L.D. y Manzo-Ugas, G. Las desviaciones del sistema económico constitucional y el ocaso económico venezolano. Derecho y Ciencias Sociales. Mayo -Octubre 2021. № 25 .Pgs 123-151. ISSN 1852-2971. Instituto de Cultura Jurídica y Maestría en Sociología Jurídica. Facultad de Ciencias Jurídicas y Sociales. Universidad Nacional de La Plata. Argentina.

la República, para ser analizadas en las negociaciones de Precios Acordados, a través de Sistema Informático de Administración de Precios".

Luego, la antedicha norma dispone que "El Sistema Informático de Administración de Precios Acordados dependerá de la Secretaría Técnica de las negociaciones de Precios Acordados, estará efectivamente articulado con las políticas públicas de producción, distribución comercialización, importación y administración de divisas. El suministro de información al Sistema será de obligatorio cumplimiento para los sectores público, privado y comunal". Y, finalmente, el punto más álgido de la citada norma dispone que "El margen de ganancia ordinaria debe ser el resultado del estudio sectorial y su aplicación debe ser diferenciado según la naturaleza, estacionalidad, productividad, envergadura de los actores, región o localidad, así como la oportunidad de la producción y la distribución" (Ley Constitucional de Precios Acordados, 2017).

Este mecanismo de fijación de precios es inédito y no se observa en ninguna economía de la región. Evidentemente se restringe la libertad de aquellos que forman parte de la cadena productiva cuando se hace referencia al establecimiento del margen de ganancias de la cadena de comercialización y de los costos. Si bien la intervención estatal es posible en cualquier economía, se observa que la intensidad que esta cobra en el Estado venezolano resulta cercana al control absoluto; porque se llega al punto en que el gobierno casi sustituye a la iniciativa privada en materia empresarial.

El Estado venezolano tiene, de acuerdo con su constitución, la posibilidad de intervenir en el proceso de producción de bienes y servicios para regularlo de diferentes maneras con el fin de conciliar el bienestar individual y el bienestar general. También el gobierno puede regular la circulación de los capitales por medio del establecimiento de reglas que garanticen el derecho a la propiedad a los particulares. El límite constitucional al ejercicio de tal derecho exige no lesionar a los derechos fundamentales de la sociedad en su conjunto mediante la proscripción de prácticas empresariales tales como la cartelización o el monopolio. Sin embargo, la conducta del gobierno venezolano va más allá de lo normado y apunta a intervenir en todo aquello que hace a la vida económica hasta no dejar margen alguno de libertad para el sector privado. 
Laise, L.D. y Manzo-Ugas, G. Las desviaciones del sistema económico constitucional y el ocaso económico venezolano. Derecho y Ciencias Sociales. Mayo -Octubre 2021. № 25 .Pgs 123-151. ISSN 1852-2971. Instituto de Cultura Jurídica y Maestría en Sociología Jurídica. Facultad de Ciencias Jurídicas y Sociales. Universidad Nacional de La Plata. Argentina.

4 Toma II: algunos aspectos problemáticos de la planificación centralizada de la economía de espalda a la constitución: el sistema venezolano de control de compra de divisas extranjeras

Lo referido a la intervención estatal en la fijación de precios se orienta, en buena medida, a regular a la actividad económica con el fin de evitar de que canalicen recursos financieros a la adquisición de divisas extranjeras. El control de cambios en Venezuela, en efecto, no es una novedad reciente, sino que se originó en el año 2003 (Gaceta Oficial de la República Bolivariana de Venezuela N. 37.625/2003). Asimismo, el Banco Central, el cual ejerce la función de ser el órgano rector en cuestiones de política monetaria, ha experimentado múltiples reformas (años 1943, 1960, 1974, 1983, 1984,1987, 1992, 2002 , 2005, 2009 y 2010). Con todo, aquí nos concentraremos en las reformas del año 2009 y 2010, porque se trata de aquellas que más incidieron en la disolución del sistema económico pergeñado en la Constitución de República Bolivariana de Venezuela (1999).

Situados en este contexto, sobre el Banco Central de Venezuela han ocurrido una cantidad de hechos que poseen relevancia en el sistema jurídico y en la democracia venezolana. La embestida del Poder Ejecutivo Nacional comenzó por medio del Decreto N. ${ }^{\circ}$ 2179/2015, el cual fue llamado "Decreto con Rango, Valor y Fuerza de Ley de Reforma Parcial de la Ley del Banco Central de Venezuela", publicado en la Gaceta Oficial de la República Bolivariana de Venezuela N. ${ }^{\circ} 6.211$ extraordinario. La reforma se dirigió puntualmente a cuestiones específicas, ya que no abarcó a la totalidad de la normativa de la autoridad monetaria, sino tan solo determinados artículos. Más específicamente, el Decreto N. ${ }^{\circ}$ 2179/2015 modifica el artículo $9^{\circ}$, cuya redacción actual ha quedado de la siguiente manera:

Artículo 9. El Presidente o Presidenta del Banco Central de Venezuela es la primera autoridad representativa y ejecutiva del Banco. Sin perjuicio de lo dispuesto en el Parágrafo Único del Artículo 19 del presente Decreto con Rango, Valor y Fuerza de Ley, su cargo es a dedicación exclusiva. Es designado o designada por el Presidente o Presidenta de la República para un período de siete años, siguiendo el procedimiento previsto en este Decreto con Rango, Valor y Fuerza de Ley para la integración del Directorio.

Ahora bien, cabría preguntarse, ¿cómo se llevaba a cabo el nombramiento del Presidente del Banco Central de Venezuela antes de la antedicha reforma? Se trata esto de 
Laise, L.D. y Manzo-Ugas, G. Las desviaciones del sistema económico constitucional y el ocaso económico venezolano. Derecho y Ciencias Sociales. Mayo -Octubre 2021. № 25 .Pgs 123-151. ISSN 1852-2971. Instituto de Cultura Jurídica y Maestría en Sociología Jurídica. Facultad de Ciencias Jurídicas y Sociales. Universidad Nacional de La Plata. Argentina.

un interrogante de suma relevancia, porque el presidente y el directorio del Banco Central resultan ser los garantes de la autonomía e independencia técnica del citado organismo. Pues bien, anteriormente la designación del Presidente del Banco Central de Venezuela era elaborada por el Presidente de la República, pero el candidato designado debía ser ratificado por la Asamblea Nacional para asumir su cargo. Dicho de otra manera, el Poder Ejecutivo Nacional tenía la iniciativa, pero no última palabra en lo que respecta a la designación de las autoridades del Banco Central.

Cabe aclarar que la ley regulatoria del Banco Central fue puesta en vigencia el 4 de septiembre de 2001, la que fue llevada a cabo por orden de la Asamblea Constituyente de 1999, la cual derogó a la ley del 4 de diciembre de 1992. Posteriormente, esa ley de 2001 fue reformada en 2005, 2009, 2010, 2014 y la última en 2015. En síntesis, la sola cantidad de veces en que ha sido modificada la ley de la autoridad bancaria central revela el desorden en que se encuentra este órgano rector de la política monetaria y, por añadidura, se advierte un caos en uno de los segmentos más significativa de la economía venezolana. El punto en que convergen las distintas reformas que atravesó la ley del Banco Central de Venezuela, incluyendo la del 30 de diciembre de 2015, es que todas estaban dirigidas a que se estableciera una suerte de enlace comunicativo entre la designación de sus autoridades y el Poder Ejecutivo, pero disminuyendo progresivamente la injerencia de la Asamblea Nacional. De esta manera, el órgano de control político por excelencia; esto es, el poder legislativo, ha sido progresivamente desplazado en el proceso de selección de los altos funcionarios que conducen al Banco Central de la República Bolivariana de Venezuela. Este escenario ha minado la autonomía e independencia política y técnica del Banco Central, el cual termina estando sometido a los designios del Poder Ejecutivo Nacional.

Cabe subrayar que la propia Constitución de la República Bolivariana de Venezuela, en su disposición transitoria octava, ha previsto algunas pautas en la designación del Presidente y los miembros del directorio del Banco Central. Más en concreto, tal disposición estableció que "una ley establecerá los términos de participación del Poder Legislativo Nacional en la designación y ratificación de estas autoridades”. En efecto, los miembros del Banco Central de Venezuela representan a los intereses de la nación y no a las posiciones de una determinada facción política. Dicho de otra manera, las autoridades del Banco Central han de tener un criterio político, en el sentido de política gubernamental o arquitectónica, pero 
Laise, L.D. y Manzo-Ugas, G. Las desviaciones del sistema económico constitucional y el ocaso económico venezolano. Derecho y Ciencias Sociales. Mayo -Octubre 2021. № 25 .Pgs 123-151. ISSN 1852-2971. Instituto de Cultura Jurídica y Maestría en Sociología Jurídica. Facultad de Ciencias Jurídicas y Sociales. Universidad Nacional de La Plata. Argentina.

no responden a la política agonal o a la lucha por adquisición, mantenimiento e incremento del poder político ${ }^{11}$.

Lo dicho anteriormente tiene como propósito asegurar que el directorio cuente con suficiente autonomía e imparcialidad política, tal como lo dispone el artículo 320 de la constitución venezolana, el cual dispone que el Banco Central "no estará subordinado a directivas del Poder Ejecutivo y no podrá convalidar o financiar políticas fiscales deficitarias", con el fin de garantizar el equilibrio necesario entre el Poder Legislativo y el Poder Ejecutivo (Brewer-Carías, 2016). Por ello tradicionalmente la Asamblea Nacional fue la que legisló y nombró —o al menos - ratificó a los directores y presidentes del Banco Central de Venezuela con el propósito de asegurar siempre el régimen de la "participación" del órgano legislativo en la designación y remoción del Presidente y miembros del Directorio del Banco Central. Se trata, ni más ni menos, de asegurar el control político parlamentario en la designación y remoción de las máximas autoridades de la entidad pública que se encarga de conducir la política monetaria de la nación.

\subsection{Toma III: el control judicial de constitucionalidad sobre el procedimiento de selección} del Presidente y miembros del Directorio del Banco Central de la República Bolivariana de Venezuela

La controversia legislativa entre el decreto del Poder Ejecutivo y la ley emitida por la Asamblea Nacional tuvo su punto máximo con la decisión de la Sala Constitucional del Tribunal Supremo de Justicia, del 31 de marzo de 2016 en el Exp. N. ${ }^{\circ}$ 16-0279. En tal sentencia se declaró la nulidad de la ley emitida por el órgano legislativo y, además, ratificó que el decreto ley del Poder Ejecutivo Nacional es la norma que se ha de aplicar para nombrar y remover al Presidente y Directores del Banco Central.

La sentencia que se analizará contiene un cierto sesgo político-partidario que se advierte a primera vista. Por ejemplo, la sentencia tan solo toma en consideración a las leyes del Banco Central puestas en vigencia durante los años de la denominada "Revolución Bolivariana" y, además, omite toda consideración a la ley emitida por la Asamblea Nacional, yendo en contra de lo expresamente dispuesto por la propia Constitución de la

11 El uso de la distinción entre política gubernamental y política agonal refiere un tanto libremente a aquella que elaboró García Pelayo. De esta manera, la política gubernamental refiere a la conducción de los asuntos públicos y la política agonal designa a la lucha por el poder bajo ciertas reglas que implican el reconocimiento de la existencia del adversario; esto es, la lucha agonal por el poder no apunta a la anulación del contrincante sino al sometimiento del poder político a ciertas reglas preestablecidas (García-Pelayo, 1983). 
Laise, L.D. y Manzo-Ugas, G. Las desviaciones del sistema económico constitucional y el ocaso económico venezolano. Derecho y Ciencias Sociales. Mayo -Octubre 2021. № 25 .Pgs 123-151. ISSN 1852-2971. Instituto de Cultura Jurídica y Maestría en Sociología Jurídica. Facultad de Ciencias Jurídicas y Sociales. Universidad Nacional de La Plata. Argentina.

República Bolivariana de Venezuela (Brewer-Carías, 2016). De esta manera, no se aprecia en tal sentencia sino la voluntad de ratificar el control político del presidente sobre el Banco Central de Venezuela, con el fin de anular a la autonomía del citado ente.

Brewer-Carías, en efecto, observó que para establecer tal acción inédita e inconstitucional se siguió una precisa estrategia argumentativa. En efecto, la Sala Constitucional del Tribunal Supremo de Justicia se limitó a examinar la constitucionalidad de la Ley de reforma de la Ley Orgánica del Banco Central de Venezuela, de 3 de marzo de 2016, a partir de las denuncias formuladas por el Presidente. Estas fueron, en síntesis, cuatro:

(i) La Asamblea Nacional había actuado “con desviación de poder", porque la finalidad de la reforma no fue sino la de limitar al poder legislativo, el cual estaba compuesto mayoritariamente por los diputados del partido opositor (Brewer-Carías, 2016).

(ii) El hecho de conferir a la Asamblea Nacional una atribución para designar las autoridades del Banco Central de Venezuela rebasa la exigencia establecida en la Constitución, la cual solo indica que el órgano legislativo ha de "participar" en la designación de los funcionarios. De manera que el órgano legislativo se habría excedido al no limitarse a refrendar a los funcionarios designados por el Poder Ejecutivo Nacional (Brewer-Carías, 2016).

(iii) La reforma "menoscaba la autonomía del Banco Central de Venezuela, al pretender limitar sus funciones e impedir el logro de los objetivos de la política macroeconómica diseñada por el Gobierno Nacional” (Brewer-Carías, 2016).

(iv) La reforma "quebranta el principio de separación de poderes" (Brewer-Carías, 2016).

El cuarto punto es el que más puede dejar perplejo al observador externo. Porque luego de analizar la historia de las regulaciones sobre el Banco Central de Venezuela, y las normas que aseguran su autonomía en la Constitución y su tradicional no subordinación al Poder Ejecutivo Nacional, la Sala Constitucional incurrió en un auténtico salto lógico. Porque, según el máximo órgano judicial de ejercer el control de constitucional en Venezuela, de la ausencia de una norma constitucional que permita que la Asamblea Nacional participe en el proceso de designación de los directores del Banco Central sigue que resulta prohibido que el órgano legislativo intervenga activamente en tal proceso. Más en concreto, el Tribunal Supremo de Justicia afirma lo siguiente: "la autonomía que le consagra la Constitución al Banco Central de Venezuela lo obliga a dirigir sus políticas en función del Plan Nacional de Desarrollo y coadyuvar con el Ejecutivo Nacional como organismo 
Laise, L.D. y Manzo-Ugas, G. Las desviaciones del sistema económico constitucional y el ocaso económico venezolano. Derecho y Ciencias Sociales. Mayo -Octubre 2021. № 25 .Pgs 123-151. ISSN 1852-2971. Instituto de Cultura Jurídica y Maestría en Sociología Jurídica. Facultad de Ciencias Jurídicas y Sociales. Universidad Nacional de La Plata. Argentina.

técnico en el diseño y ejecución de las políticas macroeconómicas, financieras y físcales" (Venezuela, TSJ, 2016).

El razonamiento que despliega el TSJ venezolano resulta muy sorprendente porque el segundo Plan Nacional de Desarrollo (2013-2019) fue elaborado sin la intervención del órgano legislativo. Por ende, la autonomía del Banco Central estaría supeditada a concretar el plan económico y a colaborar con la política económica que elabora unilateralmente el Ejecutivo Nacional, pero que este pone por fuera del órgano de control político por excelencia: la Asamblea Nacional. Cabe aclarar que no existe ninguna disposición jurídica que imponga al Banco Central la obligación de colaborar e implementar un determinado plan económico ideado por la Presidencia de la Nación. Lo cual, además, se torna especialmente grave en tanto y en cuanto se conculcan las libertades económicas que reconoce la propia Constitución de la República Bolivariana de Venezuela.

\section{Balance conclusivo: el ocaso económico venezolano como resultado de las desviaciones constitucionales de sus postulados económicos fundamentales}

El proceso de conculcación de los postulados económicos de la Constitución venezolana, para el momento en que culmina esta investigación, se encuentra francamente avanzado. De hecho, se ha llegado a un punto tal en que la cooptación de las designaciones del Banco Central de la República Bolivariana de Venezuela no solo responde a los intereses de la facción política que lidera el Poder Ejecutivo Nacional. Más grave aún, en términos institucionales, es que la autoridad monetaria se abstenga de publicar información estadística oficial que refleje fielmente el estado de las finanzas públicas. Ese dato resulta de la máxima importancia para ejercer un control político tanto por la Asamblea Nacional como por los ciudadanos de a pie.

Las disposiciones infraconstitucionales que, por ejemplo, pretenden determinar los márgenes de ganancias al ejercer una industria lícita; o bien socavar los sistemas de control y contrapeso que limitan el poder del gobierno del Estado, se han dirigido a afianzar una voluntad autoritaria o autocrática. Lo cual pretende imponer un determinado esquema económico que le da la espalda al pacto social que la república venezolana oportunamente se dio a través de su constitución. De esta manera, el orden económico contenido en el texto constitucional se encuentra a la deriva; esto es, sin un claro rumbo que ubique a Venezuela en una senda de progreso y prosperidad socioeconómica. 
Laise, L.D. y Manzo-Ugas, G. Las desviaciones del sistema económico constitucional y el ocaso económico venezolano. Derecho y Ciencias Sociales. Mayo -Octubre 2021. № 25 .Pgs 123-151. ISSN 1852-2971. Instituto de Cultura Jurídica y Maestría en Sociología Jurídica. Facultad de Ciencias Jurídicas y Sociales. Universidad Nacional de La Plata. Argentina.

El fracaso económico venezolano ha llegado a niveles sin precedentes, lo que repercutió en la calidad de vida de sus habitantes hasta alcanzar niveles paupérrimos. De hecho, por lejos, Venezuela posee el índice inflacionario más alto del mundo. Correlativamente, el grado de cumplimiento de los derechos humanos de los venezolanos ha llegado a niveles magros y altamente deficientes, tal como lo advierte el último informe del Comité de Derechos Humanos de la ONU, redactado por Michel Bachelet. Las migraciones masivas de los venezolanos, muchas veces recorriendo cientos de kilómetros a pie, no son sino uno de los signos que revela la profundad de crisis humanitaria que sufre Venezuela.

La práctica macroeconómica venezolana se ha ido alejando cada vez más de lo dispuesto en la Constitución de la República Bolivariana de Venezuela. Esto significa que el propio modelo socioeconómico que se ha dado en llamar como 'Revolución Bolivariana' se ha plasmado en un conjunto de aspiraciones sociales, políticas y económicas que se está dejando de lado. La superación tanto del individualismo egoísta o posesivo y del colectivismo que reduce a la persona humana a la mera condición de instrumento ha quedado a la deriva. La persona humana termina siendo vulnerada en el núcleo más básico de su dignidad humana al verse provista de una moneda cuyo valor se deprecia cada día como ninguna otra en el mundo - 319\% más rápido que en Zimbawe, el país que ostenta el segundo puesto-.

Las libertades económicas también se ven fuertemente intervenidas por el Estado al momento de ejercer una industria lícita. Porque es el gobierno del Estado el que determina el margen de ganancias que le corresponde a cada empresa y es este quien otorga la autorización para adquirir divisas extranjeras, las cuales son sencillamente imprescindibles para la producción de bienes y servicios en un país tan dependiente de la producción de hidrocarburos.

Por último, el Banco Central de Venezuela ha perdido toda autonomía técnica, independencia política y, lo que es peor aún, ha renunciado a su voluntad de proporcionar información macroeconómica oficial de calidad técnica. No es que sus estadísticas sean parcializadas, sesgadas o insuficientes. El Banco Central de Venezuela, por ejemplo, ha dejado de publicar información mínimamente confiable en materia de inflación, indicadores de macroeconomía y, en general, solo da a conocer algo cuando está estrechamente relacionado a decisiones emanadas directamente por el Poder Ejecutivo de la Nación. El órgano legislativo perdió toda capacidad de llevar a cabo el control político del Banco Central y su Junta de Directores ahora es nombrada sin intervención alguna de 
Laise, L.D. y Manzo-Ugas, G. Las desviaciones del sistema económico constitucional y el ocaso económico venezolano. Derecho y Ciencias Sociales. Mayo -Octubre 2021. № 25 .Pgs 123-151. ISSN 1852-2971. Instituto de Cultura Jurídica y Maestría en Sociología Jurídica. Facultad de Ciencias Jurídicas y Sociales. Universidad Nacional de La Plata. Argentina.

la Asamblea Nacional. Dicho de otra manera, la Banca Central resulta ser una suerte de cartera ministerial más de la Presidencia de la República Bolivariana de Venezuela.

En efecto, las operaciones que normalmente realiza cualquier banco central en Venezuela han sido silenciadas y basta con mirar la caída de las reservas internacionales para concluir que esta institución ha quedado sometida a un proceso que ha disminuido por completo sus capacidades y competencias. El Banco Central de Venezuela ya no es una autoridad monetaria idónea y técnicamente independiente, sino una instancia de ejecución de la voluntad presidencial en los asuntos que atañen a la política monetaria del Estado.

\section{Bibliografía}

Aguilar Blancas, C. A. (2017). Alcances y perspectivas del control parlamentario en la democracia mexicana. Estudios Políticos, 51, 36-56. https://doi.org/10.17533/udea.espo.n51a03

Aragón Reyes, M. (1986). El control parlamentario como control político. Revista de Derecho Político, 23, 11-39. https://doi.org/10.5944/rdp.23.1986.8335

Arendt, H. (1958). The Origins of Totalitarianism. Cleveland: Meridian Books.

Aristotle (2014). Complete Works of Aristotle, Volume 2: the Revised Oxford Translation (J. Barnes (ed.); E. S. Forster (trans.). Princeton University Press. https://doi.org/10.1515/9781400835843

Asamblea Nacional de la República Bolivariana de Venezuela. (2017). Acuerdo sobre la inflación y su incidencia social en la familia venezolana. Recuperado de: http://www.asambleanacional.gob.ve/actos/detalle/acuerdo-sobre-la-inflacion-y-suincidencia-socialen-la-familia-venezolana-97

Astudillo Moya, M. (2012). Fundamentos de economía. UNAM, Instituto de Investigaciones Económicas. Recuperado de: http://ru.iiec.unam.mx/2462/1/FundamentosDeEconomiaSecuenciaCorrecta.pdf

Bobbio, N. (2000). Ni con Marx, ni contra Marx. México D. F.: Fondo de Cultura Económica.

Brewer-Carías, A. R. (2016). La sentencia de muerte poder legislativo en Venezuela. El cinismo de la Sala Constitucional y la inconstitucional pretensión de controlar la actividad política de la Asamblea Nacional al reformar la Ley del Banco Central de Venezuela. Recuperado de: http://allanbrewercarias.net/Content/449725d9-f1cb474b-8ab2-41efb849fea3/Content/Brewer. La sentencia de muerte AN. Sentencia SC Ley BCV.pdf

Brum, P. (2011). El impacto del totalitarismo en el siglo XX. http://hdl.handle.net/20.500.11968/2776

Chávez Frías, H. (2008). Proyecto nacional Simón Bolivar. Primer plan socialista -PPS-. Recuperado de: https://www.paho.org/es/documentos/venezuela-proyecto-nacionalsimon-bolivar-2007-2013 
Laise, L.D. y Manzo-Ugas, G. Las desviaciones del sistema económico constitucional y el ocaso económico venezolano. Derecho y Ciencias Sociales. Mayo -Octubre 2021. № 25 .Pgs 123-151. ISSN 1852-2971. Instituto de Cultura Jurídica y Maestría en Sociología Jurídica. Facultad de Ciencias Jurídicas y Sociales. Universidad Nacional de La Plata. Argentina.

Constitución de la República Bolivariana de Venezuela, (1999).

Fazio, F. de (2019). Teoría principalista de los derechos sociales. Madrid - Buenos Aires: Marcial Pons.

Finnis, J. (2013). The Priority of Persons Revisited. The American Journal of Jurisprudence, 58(1), 45-62. https://doi.org/10.1093/ajj/aut003

FMI. (2020). Inflation rate, average consumer prices. IMF DataMapper. Recuperado de: https://www.imf.org/external/datamapper/PCPIPCH@WEO/WEOWORLD/VEN

FMI, Departamento de Comunicaciiones. (2018). Declaración del Directorio Ejecutivo del FMI sobre la República Bolivariana de Venezuela. Comunicado de Prensa No 18/158. https://www.imf.org/es/News/Articles/2018/05/02/pr18158-statement-bythe-imf- Recuperado de: executive-board-on-venezuela

García-Pelayo, M. (1983). Idea de la política y otros escritos. Centro de Estudios Constitucionales y Políticos.

Gargarella, R. (2011). Grafting Social Rights onto Hostile Constitutions. Texas Law Review, 89(7), 1537-1556. Recuperado de: https://www.corteidh.or.cr/tablas/r27166.pdf

Hervada, J. (2011). Introducción crítica al derecho natural. In 1981 (11 Ed.). Pamplona: EUNSA. Recuperado de: https://dadun.unav.edu/bitstream/10171/56681/1/02Introducción crítica al derecho natural.pdf

Infobae. (2020, 8 de Julio). Inflación en 12 meses en Venezuela se ubica en $3.524 \%$ a junio, según el Parlamento. Infobae.Com. Recuperado de: https://www.infobae.com/america/agencias/2020/07/08/inflacion-en-12-meses-envenezuela-se-ubica-en-3524-a-junio-segun-el-parlamento/

Jiménez Ramírez, M. C. (2016). Estado social de derecho y mercado. Una aproximación a una relación constitucional. Pensamiento Constitucional, 21(21), 187-218. Recuperado de: http://revistas.pucp.edu.pe/index.php/pensamientoconstitucional/article/view/18705/ 18946

Leon, D. S. (2020). Violence in the Barrios of Caracas: Social Capital and the Political Economy of Venezuela. Dodrecht: Springer. Recuperado de: https://doi.org/10.1007/978-3-030-22940-5

Loey, F. (2020, 18 de Junio). Coronavirus, vacuna, desplazados... Las noticias del jueves | Noticias ONU. Noticias ONU. Recuperado de: https://news.un.org/es/story/2020/06/1476192

Mejía-Ortega, L. M., \& Franco-Giraldo, Á. (2007). Protección Social y Modelos de Desarrollo en América Latina. Revista de Salud Pública, 9(3), 471-483. https://doi.org/10.1590/S0124-00642007000300016

Palacios Ramsbotton, M. (2019). "Gorka Lalaguna: existen notables discrepancias en cifras del INPC que anuncia el BCV”. Recuperado de: https://cotejo.info/2019/06/cifras-bcv-en-entredicho/

Rosales, E. (2006). Sistema penal y reforma legal en Venezuela: la tension entre el Estado constitucional y el Estado policial. Revista Cenipec, 25, 175-230. Recuperado de: 
Laise, L.D. y Manzo-Ugas, G. Las desviaciones del sistema económico constitucional y el ocaso económico venezolano. Derecho y Ciencias Sociales. Mayo -Octubre 2021. № 25 .Pgs 123-151. ISSN 1852-2971. Instituto de Cultura Jurídica y Maestría en Sociología Jurídica. Facultad de Ciencias Jurídicas y Sociales. Universidad Nacional de La Plata. Argentina.

http://www.saber.ula.ve/bitstream/handle/123456789/23560/articulo6.pdf?sequence= 2\&isAllowed $=\mathrm{y}$

Rugholm, D. (2018). Hay una crisis alimentaria en la frontera entre Venezuela y Colombia. Noticias ONU. Recuperado de: https://news.un.org/es/story/2018/04/1432282

Santiago, A. (1999). La Corte Suprema y el control político: función política y posibles modelos institucionales. Buenos Aires: Ábaco.

Tinker Salas, M. (2015). Venezuela: What Everyone Needs to Know. New York: Oxford University Press.

Torrealba Méndez, C. G. (2019). Venezuela: contexto, análisis y escenarios. Revista Mexicana de Sociología, 81, 443-455. Recuperado de: http://www.scielo.org.mx/pdf/rms/v81n2/2594-0651-rms-81-02-443.pdf

U. N. O. on Druges and Crime. (2019). Global Study on Homicide: Homicide trends, patterns and criminal justice response (Vol. 20). Recuperado de: https://doi.org/10.1023/B:JOQC.0000037731.28786.e3

Valeriano García, F. (2000). Para entender la economía política: y la política económica. México D. F: Centro de Estudios Monetarios Latinoamericanos. Recuperado de: https://www.cemla.org/PDF/estudios/pub-lib-vg.pdf

Vargas J. et. al. (2019) "Informaciòn financiera VS. realidad Económica". Recuperado de: https://e-learningvzla.com.ve/blog/informacion-financiera-vs-realidad-economica

Venezuela. Sala Constitucional. Tribunal Supremo de Justicia, magistrado ponente: Calixto Ortega Ríos. Sentencia del 31 de marzo de 2016, Exp. N. ${ }^{\circ}$ 16-0279. Recuperado de: http://historico.tsj.gob.ve/decisiones/scon/marzo/186656-259-31316-2016-20160279.HTML

Venezuela. Sala Constitucional. Tribunal Supremo de Justicia, magistrado ponente: Héctor Rodríguez Castro. Sentencia del 25 de julio de 2019, Exp: 17-0001. Recuperado de: https://accesoalajusticia.org/\%ef\%bb\%bftsj-declara-nulo-acuerdo-del-parlamentopara-designar-directorio-ad-hoc-del-bcv/

Zubillaga, V. (2013). Menos desigualdad, más violencia: la paradoja de Caracas. Nueva Sociedad, 243, 105-118. https://nuso.org/articulo/menos-desigualdad-mas-violenciala-paradoja-de-caracas/ 